Article

\title{
Biolubricants from Rapeseed and Castor Oil Transesterification by Using Titanium Isopropoxide as a Catalyst: Production and Characterization
}

\author{
José María Encinar ${ }^{1}\left(\mathbb{D}\right.$, Sergio Nogales-Delgado ${ }^{1, * \mathbb{C}}$, Nuria Sánchez ${ }^{1}$ and Juan Félix González ${ }^{2}$ \\ 1 Department of Chemical Engineering and Physical-Chemistry, University of Extremadura, 06006 Badajoz, \\ Spain; jencinar@unex.es (J.M.E.); nuriass@unex.es (N.S.) \\ 2 Department of Applied Physics, University of Extremadura, 06006 Badajoz, Spain; jfelixgg@unex.es \\ * Correspondence: senogalesd@unex.es
}

Received: 4 March 2020; Accepted: 26 March 2020; Published: 29 March 2020

check for updates

\begin{abstract}
The transesterification of rapeseed and castor oil methyl esters with different alcohols (2-ethyl-1-hexanol, 1-heptanol and 4-methyl-2-pentanol) and titanium isopropoxide as a catalyst, to produce biolubricants, was carried out. Parameters such as temperature, alcohol/methyl ester molar ratio, and catalyst concentration were studied to optimize the process. The reaction evolution was monitored with the decrease in FAME concentration by gas chromatography. In general, the reaction was almost complete in two hours, obtaining over $93 \%$ conversions. All the variables studied influenced on the reaction yields. Once the optimum conditions for the maximum conversion and minimum costs were selected, a characterization of the biolubricants obtained, along with the study of the influence of the kind of alcohol used, was carried out. The biolubricants had some properties that were better than mineral lubricants (flash points between 222 and $271{ }^{\circ} \mathrm{C}$ ), needing the use of additives when they do not comply with the standards (low viscosity for rapeseed biolubricant, for instance). There was a clear influence of fatty acids of raw materials (oleic and ricinoleic acids as majority fatty acids in rapeseed and castor oil, respectively) and the structure of the alcohol used on the final features of the biolubricants.
\end{abstract}

Keywords: fatty acid methyl esters; 2-ethyl-1-hexanol; 1-heptanol; 4-methyl-2-pentanol; viscosity; flash and combustion points; methyl oleate; methyl ricinoleate

\section{Introduction}

The main objective of lubrication is the protection of surfaces in close proximity and moving relative to each other. This protection is carried out by interposing a substance (lubricant) between the abovementioned surfaces. This way, the use of lubricants is important to reduce wear, avoiding corrosion and reducing oxidation in surfaces [1]. Consequently, lubricants are essential in industrial processes. However, petro-based lubricants, which are extensively used, contribute to many environmental and sustainability problems [2]. In addition, the scarcity of crude oil reserves provokes the increase in prices, which makes sustainability and development of poor areas more difficult. This way, the search for alternative, sustainable, and biodegradable products is becoming more and more necessary. Thus, biolubricants (mainly derived from vegetable oils) are gaining in importance, as they can be used in many applications, being environmental friendly (that is, biodegradable, with low ecotoxicity and not contributing to volatile organic chemicals) [1-3]. Moreover, the fatty acid component of biolubricants can form layers and a stable film on the surfaces of rubbing zones, avoiding the contact between surfaces and therefore, corrosion and wear [4]. Many raw materials (such as rapeseed or castor) could contribute to the sustainable development, being an alternative to rotate typical crops in many regions 
and being an alternative to petroleum fuels or products and, consequently, a key for the development of local economies [5-8]. Indeed, they have been used as raw materials for biolubricant production from different ways $[1,9,10]$. However, the low temperature properties and oxidation stability of these biolubricants make extensive use difficult [11]. In general, vegetable oils are mainly composed of fatty acids. Thus, oleic, linoleic, linolenic, or ricinoleic acid play an important role in some typical vegetable oils, such as rapeseed, safflower, sunflower, corn, or castor oil. Thus, the specific composition of these vegetable oils can vary depending on the kind of oil or pre-harvest conditions such as soil, climate, etc [2]. Consequently, the characteristics of these vegetable oils (and their derivatives, such as fatty acid methyl esters), especially some properties such as viscosity or oxidative stability, depend on the percentages of these components $[1,5,12-14]$. Oleic acid, with one unsaturation in its molecular structure, promotes high oxidative stabilities, whereas ricinoleic acid increases viscosity due to the hydroxyl group in its structure. As a result, many properties of these fatty acids depend on the stereochemistry of the molecular chains, the length and degree of branching or unsaturation, among other factors [2,15-17]. Concerning biolubricant production, there are plenty of chemical reactions to obtain them, especially epoxidation and double transesterification (from triglycerides to fatty acid complex esters, through fatty acid methyl esters) $[1,13,18]$. Thus, transesterification is a chemical reaction between an ester and an alcohol to transform the former into another ester by interchanging alkyl groups. It can be classified into acid or base-catalyzed reactions, depending on the catalyst used. The complexity of the final ester obtained (and their characteristics as a biolubricant) is dependent on the nature of the alcohol used for the chemical reaction [1]. Thus, the use of catalysts is necessary, especially when the alcohol used in this transesterification is complex (especially when biolubricants are produced), which makes transesterification difficult. The aim of this research work was to optimize temperature, alcohol/FAME ratio, and catalyst concentration for the suitable production of biolubricants from two typical vegetable oils in Spain, assessing the effect of the raw material and the kind of alcohol used in biolubricant features. This research work could lead to a sustainable production of biolubricants from local feedstocks.

\section{Results and Discussion}

\subsection{Raw Material Characterization}

In order to determine the biolubricant yield, gas chromatography coupled to FID detection was carried out. In this case, the decrease in total FAME content over time was used to determine the yield of biolubricant production. FAME distribution, after the first transesterification (see Figure 1), was similar to previous studies with the same oils, observing slight differences $[6,12,16,19]$. For rapeseed oil, the majority ester was methyl oleate $(63.07 \%)$, followed by methyl linoleate $(21.15 \%)$, and linolenate $(8.71 \%)$. On the other hand, other FAMEs (methyl myristate, palmitoleate, and erucate) hardly constitute $0.5 \%$. Initially, total FAME content was $96.59 \%$. On the other hand, castor oil presented high proportions of methyl ricinoleate (over $88 \%$ ), and the other FAMEs were scarce, with methyl linoleate being the second most abundant one (4.5\%).
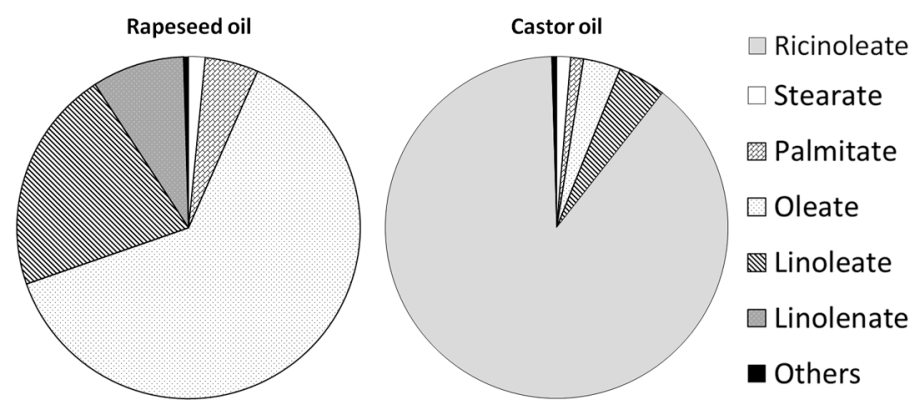

Figure 1. FAME profile of biodiesel from rapeseed and castor oils. 
In general, fatty acid methyl ester distribution, as it occurred in biodiesel composition, could play an important role in the behavior of the subsequent biolubricants $[14,16,20]$. This is important in the case of castor oil where, as indicated, there was a notorious majority in methyl ricinoleate. Effectively, according to Table 1 , there were clear differences between the samples, especially concerning viscosity. For rapeseed oil methyl esters, similar values for methyl oleate (between 3.73 and $4.51 \mathrm{cSt}$ ) were found in the literature. It must be pointed out that methyl oleate is the main FAME in rapeseed oil biodiesel, and many of its physical and chemical characteristics could influence rapeseed biodiesel. In addition, methyl linoleate, with a double unsaturation, could contribute to low viscosity values [16]. On the other hand, castor oil FAMEs had an extremely high viscosity. This fact could be explained by the structure of the main FAME after the first transesterification. That way, viscosity increases proportionally with the presence of hydroxyl groups, which is the distinguishing characteristic of ricinoleic acid. As it is the main fatty acid in castor oil, this could explain the high viscosity found for the corresponding FAMES of this oil [16].

Table 1. Characteristics of FAMES from rapeseed and castor oils.

\begin{tabular}{ccc}
\hline Parameter & Rapeseed FAME & Castor oil FAME \\
\hline Density $\left(\mathrm{kg} / \mathrm{m} 3\right.$ at $\left.15^{\circ} \mathrm{C}\right)$ & 878.23 & 916.20 \\
Viscosity $\left(\mathrm{cSt}\right.$ at $\left.40^{\circ} \mathrm{C}\right)$ & 5.32 & 15.8 \\
Acid number $(\mathrm{mg}$ & 0.175 & 0.875 \\
$\mathrm{KOH} / \mathrm{g})$ & & \\
\hline
\end{tabular}

\subsection{Influence of Temperature}

Concerning the influence of temperature on biolubricant yield (Figure 2), it can be seen that the worst performance was related to $150{ }^{\circ} \mathrm{C}$, obtaining $89 \%$ at the end of the experiment. For $160{ }^{\circ} \mathrm{C}$ and $170{ }^{\circ} \mathrm{C}$, over $90 \%$ of the reaction was completed after $60 \mathrm{~min}$, reaching in both cases similar final yields ( $94.26 \%$ and $95.38 \%$, respectively), albeit the reaction at $170{ }^{\circ} \mathrm{C}$ was kinetically faster. Moreover, after $60 \mathrm{~min}$, an asymptotic behavior was observed for these experiments. This way, a clear influence of temperature was observed, not only on final yield, but also on kinetics, especially if temperatures were too low. Accordingly, from an economic point of view, $160{ }^{\circ} \mathrm{C}$ was the recommended temperature for further studies.

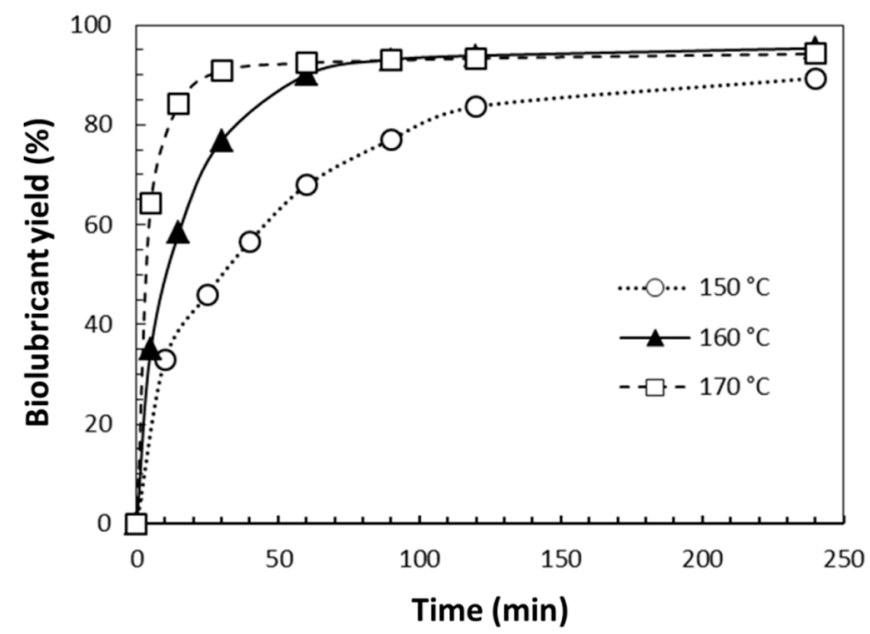

Figure 2. Biolubricant production depending on temperature ([Catalyst $]=1 \% \mathrm{w} / \mathrm{w}$; alcohol $=$ 2-ethyl-1-hexanol; molar ratio $=3: 1$ ).

\subsection{Influence of Catalyst Concentration}

The influence of catalyst concentration (see Figure 3) was determined at $150^{\circ} \mathrm{C}$, considering that at low temperatures, the concentration of catalyst would be more decisive. From a kinetic point of 
view, the concentration of catalyst exerted a positive effect on the reaction rate. Taking into account the biolubricant yield, with $0.5 \%$ catalyst $(\mathrm{w} / \mathrm{w})$, the final conversion was too poor (under $80 \%$ ) compared to $1 \%$ and $2 \%(89.40 \%$ and $90.18 \%$, respectively). For $1 \%$ and $2 \%$ of catalyst, the reaction was almost complete after two hours, reaching an asymptotic curve from then on. There seemed to be a maximum catalyst concentration, from which no improvement in conversion was observed. On this basis, the most suitable catalyst concentration was $1 \% \mathrm{w} / \mathrm{w}$.

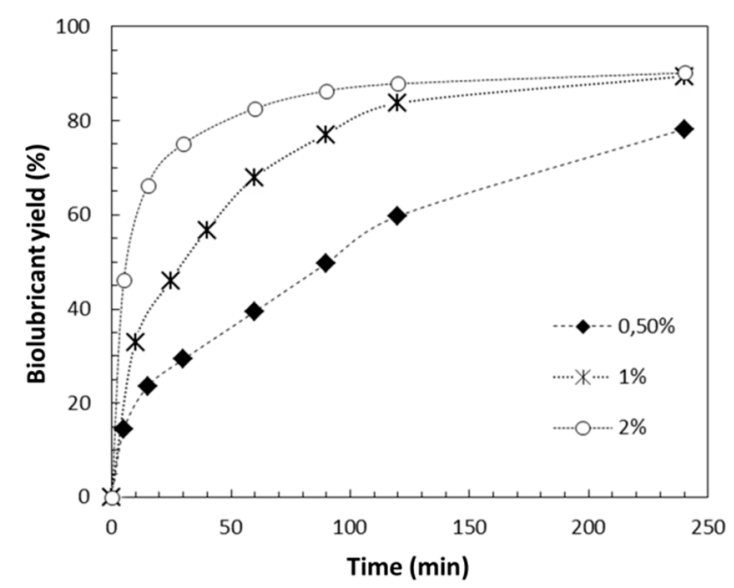

Figure 3. Biolubricant production depending on catalyst concentration. (Temperature $=150{ }^{\circ} \mathrm{C}$; alcohol = 2-ethyl-1-hexanol; molar ratio $=3: 1$ ).

\subsection{Influence of Alcohol/FAME Molar Ratio}

With respect to 2-ethyl-1-hexanol/FAME molar ratio, there were differences, especially for 1:1 molar ratio (Figure 4). With this value, hardly 50\% conversion was achieved, whereas for 2:1 and 3:1, the yield was better $(81.71 \%$ and $89.40 \%$, respectively). These results confirmed that the concentration of alcohol strongly affected the equilibrium, displacing the reaction towards the formation of the biolubricant. Concerning kinetics, the influence of alcohol concentration was positive, increasing the formation rate of the final product. For this reason, some authors recommend, for transesterification reactions using FAME as substrate, an amount of alcohol slightly higher than 1:1 molar ratio [21]. In this case, the most suitable molar ratio was 3:1.

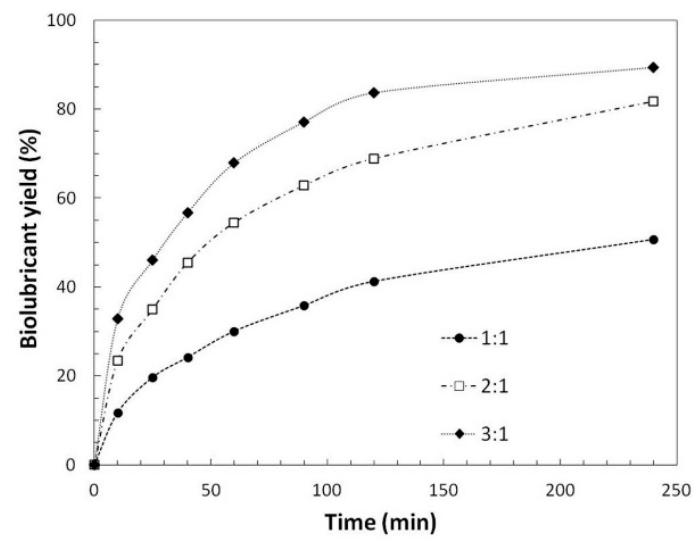

Figure 4. Biolubricant production depending on alcohol/FAME molar ratio. ([Catalyst] $=1 \% w / w$; alcohol = 2-ethyl-1-hexanol; temperature: $150{ }^{\circ} \mathrm{C}$ ).

In summary, and taking into account the above-mentioned discussion and the relationship of commitment between yield and economic criteria, the selected values for the final biolubricant production were the following: $160^{\circ} \mathrm{C}, 1 \%$ catalyst $(\mathrm{w} / \mathrm{w})$, and $3: 1$ molar ratio. 


\subsection{Biolubricant Characterization}

Once the final biolubricant was produced under these conditions $\left(160{ }^{\circ} \mathrm{C}, 1 \%\right.$ catalyst $(\mathrm{w} / \mathrm{w})$, 2-ethyl-1-hexanol and 3:1 molar ratio), a thorough characterization was carried out, obtaining for rapeseed oil biolubricant the following values: saponification number, $148.5 \mathrm{mg} \mathrm{KOH} / \mathrm{g}$; iodine number, $55.5 \% \mathrm{w} / \mathrm{w}$; moisture, $0.026 \% \mathrm{w} / \mathrm{w}$; and cold filter plugging point, $0{ }^{\circ} \mathrm{C}$. The low value for iodine number could imply a better stability of this biolubricant during storage, as the amount of unsaturations (that is, reactive points to increase oxidation) is considerably lower to those found in the literature for FAME [5].

\subsection{Influence of Raw Material on Biolubricants}

For the rest of parameters, a comparison between rapeseed (RB), castor (CB) and two commercial lubricants (L1 and L2) was carried out; the results are shown in Table 2. The commercial lubricants were mainly composed of aliphatic hydrocarbons, and their main use was for hydraulic systems, turbines, and gears. As can be observed, both biolubricants (obtained by transesterification of FAMEs with 2-ethyl-1-hexanol) were obtained with adequate yields (94-97\%) and similar density values, close to the values typically found in the literature and the commercial biolubricants. There were considerable differences in viscosity values, as mentioned earlier for the respective biofuels (especially for $\mathrm{CB}$, much higher than the rest of the samples). For rapeseed oil, a viscosity of $11 \mathrm{cSt}$ at $40^{\circ} \mathrm{C}$ was found, which does not meet most requirements of ISO norms, whereas castor oil amply complies with these requirements with $208.25 \mathrm{cSt}$ at $40{ }^{\circ} \mathrm{C}$, exceeding the lower limit of the ISO VG100 norm $(90.0 \mathrm{cSt}$ at the same temperature). These values were similar to those found in the literature for other vegetable oils used as biolubricants or derivatives [18,22]. It was possibly due to the fact that the fatty acids of biolubricants derived from rapeseed and castor oils kept a similar chemical structure, especially paying attention to the hydroxyl group in ricinoleate (majority in castor oil biolubricant), which increases its polarity and, therefore, its viscosity both at $40^{\circ} \mathrm{C}$ and $100{ }^{\circ} \mathrm{C}[16,17]$. Concerning flash and combustion points, they were high in both biolubricants, especially for castor oil. This fact implies that they are safe when it comes to storage and management, exceeding most requirements for this parameter in the case of rapeseed oil, and improving the results of the commercial lubricants [18]. Regarding the viscosity index, it could be said that both biolubricants showed multigrade characteristics (exceeding 140 , being suitable for industrial purposes), and therefore, viscosity is less variable over temperature for these products, compared to the commercial lubricants, which showed lower viscosity indexes (below 100) [23,24].

Table 2. Comparison of rapeseed and castor biolubricants *.

\begin{tabular}{ccccc}
\hline Parameter & RB & CB & L1 & L2 \\
\hline Yield $(\%)$ & 96.59 & 93.80 & - & - \\
\hline Density $\left(\mathrm{kg} / \mathrm{m}^{3}\right.$ at $\left.15^{\circ} \mathrm{C}\right)$ & 873 & 930 & 845 & 860 \\
Viscosity $\left(\mathrm{cSt}\right.$ at $\left.40{ }^{\circ} \mathrm{C}\right)$ & 10.04 & 208.25 & 7.0 & 13.8 \\
Viscosity $\left(\mathrm{cSt}\right.$ at $\left.100{ }^{\circ} \mathrm{C}\right)$ & 4.09 & 26.74 & 2.1 & 3.4 \\
Viscosity index & 377 & 163 & 97 & 95 \\
Pour point $\left({ }^{\circ} \mathrm{C}\right)$ & $<-10$ & $<-16$ & -30 & -18 \\
CFPP $\left({ }^{\circ} \mathrm{C}\right)$ & 0 & - & -27 & -18 \\
Flash point $\left({ }^{\circ} \mathrm{C}\right)$ & 222 & 271 & 150 & 180 \\
Combustion point $\left({ }^{\circ} \mathrm{C}\right)$ & 236 & 285 & - & - \\
Acid number $(\mathrm{mg} \mathrm{KOH} / \mathrm{g})$ & 0.39 & 0.45 & 0.38 & 0.50 \\
Oxidative stability $(\mathrm{h})$ & 0.94 & - & - & - \\
\hline
\end{tabular}

* Experimental conditions: Temperature $=160{ }^{\circ} \mathrm{C} ;$ [Catalyst] $=1 \% w / w ;$ 2-ethyl-1-hexanol/FAME ratio $=3: 1$

For CFPP and pour point, it could be said that, in general, the commercial lubricants showed lower (and better) values compared to the biolubricants obtained, with the values of the latter being comparable to other biolubricants [18]. The oxidative stability (data available for rapeseed biolubricant) 
was low, not exceeding one hour. Nevertheless, according to the literature, this value is in a similar order of magnitude to other biolubricants [18,24].

\subsection{Influence of Alcohol Structure on Biolubricants}

Finally, and comparing the same raw material for the production of biolubricants with different alcohols for transesterification, castor FAMEs were used with 2-ethyl-1-hexanol, 1-heptanol, and 4-methyl-2-pentanol (Table 3). In this case, there were clear differences between the biolubricant obtained by the reaction of castor FAME with 2-ethyl-1 hexanol and the rest of the alcohols. It has already been reported that the number of carbons or branching in the alcohol chain structure could also influence properties such as viscosity $[17,25]$. However, some authors do not consider this fact as a determinant, finding some functional groups (such as phenyl) more influential [10]. Thus, the complexity of 2-ethyl-1-hexanol structure is able to promote more intermolecular bonds, increasing viscosity.

Table 3. Comparison of biolubricants from castor oil FAMEs by using 2-ethyl-1-hexanol (A), 1-heptanol (B), and 4-methyl-2-pentanol (C).

\begin{tabular}{cccc}
\hline Parameter & A & B & C \\
\hline Density $\left(\mathrm{mg} / \mathrm{ml}\right.$ at $\left.15^{\circ} \mathrm{C}\right)$ & 0.930 & 0.908 & 0.912 \\
Viscosity $\left(\mathrm{cSt}\right.$ at $\left.40{ }^{\circ} \mathrm{C}\right)$ & 208.25 & 39.96 & 34.47 \\
Viscosity $\left(\mathrm{cSt}\right.$ at $\left.100^{\circ} \mathrm{C}\right)$ & 26.74 & 7.11 & 6.13 \\
\hline
\end{tabular}

* Experimental conditions: Temperature $=160^{\circ} \mathrm{C}, 150^{\circ} \mathrm{C}$, and $120^{\circ} \mathrm{C}$ for $\mathrm{A}, \mathrm{B}$, and $\mathrm{C}$, respectively; [Catalyst $]=1 \% w / w$; alcohol/FAME ratio $=3: 1$

\section{Materials and Methods}

\subsection{Raw Materials and Experimental Design}

The raw materials, rapeseed and castor oil, were provided by the Research Center "La Orden-Valdesequera" (Badajoz-Spain) Section of Non-Food (CICYTEX). These vegetable oils were the starting point of the experimental design, being quite different in physical and chemical features. An overview of the experimental design is shown in Figure 5.

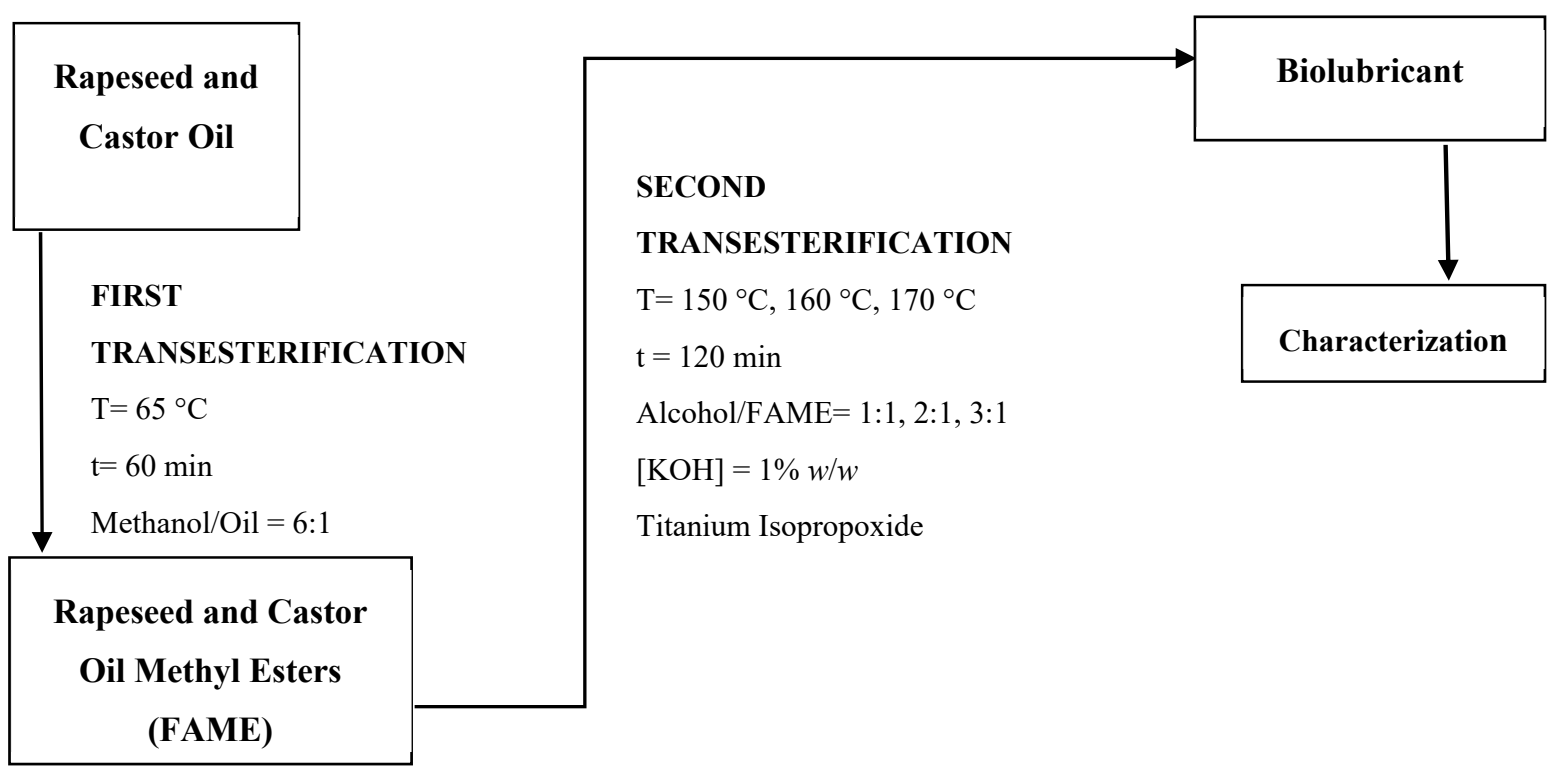

Figure 5. Experimental design.

The first transesterification produced fatty acid methyl esters (FAMEs or biodiesel), which were obtained by using optimum parameters. Afterwards, the second transesterification was carried out 
to produce fatty acid complex esters (biolubricants), assessing different temperature values, catalyst percentages, alcohol/FAME ratios, and kinds of alcohol. The characterization of the biolubricant obtained was carried out, paying attention to viscosity.

\subsection{First Transesterification}

As an intermediate stage, fatty acid methyl esters (FAME) were produced from rapeseed and castor oil. In this reaction, the triglycerides that constitute the vegetable oils react with three moles of methanol to produce three moles FAME and glycerol.

This reaction is reversible, and therefore parameters such as temperature, catalyst concentration, and molar ratio are important to obtain better FAME yields.

For this purpose, a reactor coupled to a condenser and supplied with temperature and stirring rate control was used. The reaction conditions, optimized in previous studies [26], were as follows: a reaction temperature of around $65^{\circ} \mathrm{C}$ was used (to avoid excessive methanol evaporation); the reaction took place for $60 \mathrm{~min}$ (to make sure that the FAME proportion in the final product was over $96.5 \%$ ); the methanol/oil ratio was 6:1 (according to previous studies, additional methanol was not necessary); the catalyst (potassium hydroxide) added was $1 \% w / w$ (of the total reaction medium). Following these steps, the FAME content of the product was over $96.5 \%$, complying with the standard and making it a suitable reagent for the next step (the second transesterification for biolubricant production). Details of the experimental procedure, methodology, and analytical methods can be found in previous works $[6,26]$.

\subsection{Second Transesterification Reaction (Biolubricant Production)}

Concerning biolubricant production, different alcohols (such as 2-ethyl-1-hexanol, 1-heptanol, and 4-methyl-2-pentanol; see Table 4), FAME (obtained earlier), and titanium isopropoxide (as a catalyst) were used for the second transesterification reaction (again, a reversible reaction; see Figure 2). These alcohols were chosen on account of their different structure, with different branching levels (see Table 4), in order to obtain different viscosity values for the products obtained. On the other hand, titanium isopropoxide was chosen due to its effectiveness and the use of titanium catalysts in industry, especially as the precursor of other catalysts such as $\mathrm{TiO}_{2}$ [27-29].

Table 4. Structure of the different alcohols used for the second transesterification.

$\begin{array}{ccc}\text { Alcohol } & \text { Boiling Point }{ }^{\circ} \mathrm{C} \\ \text { 2-ethyl-1-hexanol } & \text { Structure } & 180 \\ 136\end{array}$

As can be observed in Figure 6, methanol was released along with the biolubricant and its removal contributes to better biolubricant production.

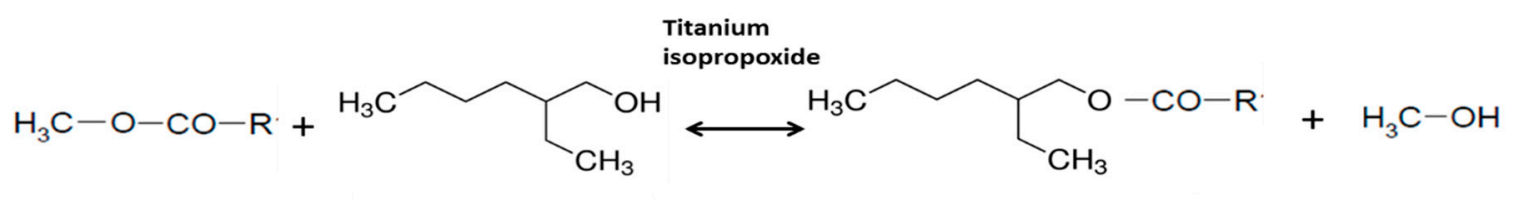

Figure 6. Second transesterification. 
As was observed in Figure 7, the experimental facility was similar to that described for the FAME production, except for the Dean Stark trap, which collects (and therefore removes from the reaction medium, improving the yield of the biolubricant) the methanol that is evolved during the second transesterification process, and the sampling point (with the aim of taking samples to analyze the FAME content evolution by gas chromatography).

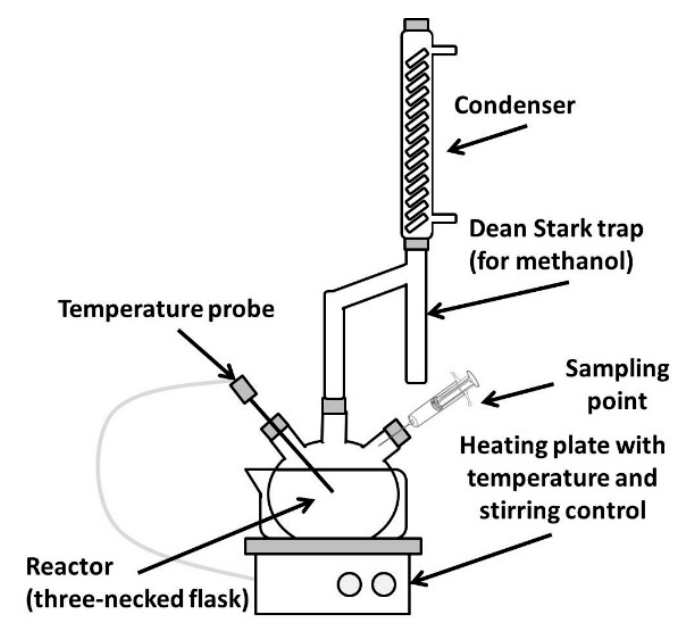

Figure 7. Experimental arrangement for biolubricant production.

In the second transesterification reaction, temperature, catalyst concentration, and molar ratio, in addition to the alcohol type, were studied for biolubricant yield optimization. Table 5 shows the range for these variables. The second transesterification process was carried out near the corresponding boiling point for each alcohol. This way, the temperature was as high as possible, not exceeding each boiling point, so that the alcohol is conserved in the reaction medium and not evaporated. In order to remove the surplus alcohol after the reaction, vacuum distillation was carried out. Figure 8 shows the experimental setup for this purpose.

Table 5. Experimental design for the optimization of biolubricant production.

\begin{tabular}{cccc}
\hline Experiment & Temperature $\left({ }^{\circ} \mathbf{C}\right)$ & Catalyst Concentration (\%) & Alcohol */FAME Molar Ratio \\
\hline $\begin{array}{c}\text { Influence of temperature } \\
\text { Influence of catalyst }\end{array}$ & 150,160 and 170 & 1 & $3: 1$ \\
concentration & 150 & $0.5,1$ and 2 & $3: 1$ \\
Influence of molar ratio & 150 & 1 & $1: 1,2: 1$ and $3: 1$ \\
\hline
\end{tabular}

${ }^{*}$ For variable optimization, 2-ethyl-1-hexanol was used.

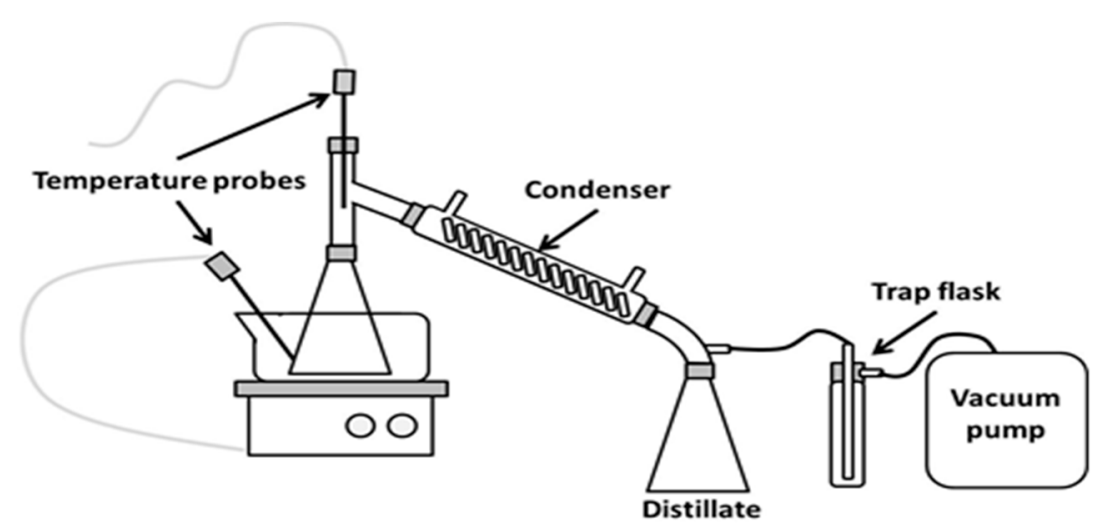

Figure 8. Biolubricant purification. 
Thus, the installation was composed of heating and stirring systems (where the lubricant is heated to remove surplus alcohol at approximately $120-150{ }^{\circ} \mathrm{C}$ ), temperature probes, a condenser, the corresponding Erlenmeyer flask to collect the alcohol, a trap flask (to protect the pump), and a vacuum pump.

To measure the decrease in FAMEs during the second transesterification reaction (implying the increase in biolubricant yield), a VARIAN 3900 chromatograph, provided with a FID, and a silica capillary column ( $30 \mathrm{~m}$ length, $0.32 \mathrm{~mm}$ ID, and $0.25 \mathrm{~mm}$ film thickness) was used. The carrier gas was helium $(0.7 \mathrm{~mL} / \mathrm{min}$ flow rate), and heptane was used as a solvent. The injector temperature was kept at $270{ }^{\circ} \mathrm{C}$ and the detector temperature at $300{ }^{\circ} \mathrm{C}$.

Temperature ramp started at $20^{\circ} \mathrm{C}$, and then went $20^{\circ} \mathrm{C} / \mathrm{min}$ up to $220^{\circ} \mathrm{C}$. A calibration curve was done for each FAME, using its corresponding standard (Sigma-Aldrich). The calibration was carried out by using an internal standard (methyl heptadecanoate).

\subsection{Biolubricant Characterization}

Once the biolubricant was obtained and purified, it was characterized. For this purpose, several determinations were carried out. Density determination was obtained by using a pycnometer. Viscosity is determined following the ISO 3104:1994 standard [30] with an Ostwald viscometer. For viscosity index, the ASTM D2270 standard was used [31]. Pour point was measured according to ATSM D-97 standard [32]. To determine cold filter plugging point (CFPP), the EN 116 standard was consulted [33]. For flash and combustion point determination, the Cleveland open-cup method was used (UNE 51-023-90) [34]. For moisture, a Metrohm 870 trinitro plus equipment was used, using the Karl-Fischer method (UNE-EN ISO 12937:2000) [35]. The saponification number was determined following the UNE-EN 55012 standard [36]. The acid number was determined according to the UNE-EN 12634:1999 standard [37]. For Iodine number, the UNE-EN 14111:2003 standard was followed [38]. The oxidative stability was obtained for biolubricant, according to the Rancimat test [39]. Thus, three grams of the sample was placed in a test tube, bubbling air $(10 \mathrm{~L} / \mathrm{h})$ into the sample, and heating it at $110^{\circ} \mathrm{C}$. The resulting stream of air, after passing through the sample, bubbled $50 \mathrm{ml}$ of deionized water. To monitor the whole process, the conductivity of this deionized water was measured. As the sample was oxidized, some by-products were developed and dissolved into the deionized water, increasing the conductivity of the latter. Thus, the induction point was determined at the time when the conductivity increased considerably.

\section{Conclusions}

The production of biolubricants (kinetics and conversion) was influenced by temperature, concentration of catalyst (titanium isopropoxide), and alcohol/FAME molar ratio. Thus, temperature slightly increased the final yield, with notorious kinetic changes at higher temperatures. Equally, the final conversion was higher, as catalyst concentration increased from low values to intermediate ones, apparently reaching a point $(1 \% w / w)$ where it was not dependent on concentration. Finally, as the molar ratio alcohol/FAME was higher, the yield was better. In order to meet both yield and economic factors, intermediate values for temperature and catalyst concentration $\left(\mathrm{T}=160^{\circ} \mathrm{C}\right.$, [Catalyst $]=1 \%$ $w / w$ ) and the highest alcohol/FAME ratio (alcohol:FAME $=3: 1$ ) were considered to be suitable for biolubricant production. Once the main parameters were optimized for biolubricant production, the yield obtained for rapeseed and castor oils was acceptable, exceeding 93\% in both cases.

The raw materials studied, rapeseed and castor oils, presented different fatty acid profiles. For the former, the majority fatty acid was oleic acid, whereas for the latter, it was ricinoleic acid. Therefore, the kind of seed selected, among other factors such as pre-harvest conditions, make this initial characterization necessary. Consequently, the proportion of fatty acids (especially the majority one), plays an important role in biolubricant features. Thus, the structure of these fatty acids, including unsaturations, length of the chain, and hydroxyl groups, influenced many parameters of the final biolubricant. For example, the presence of a hydroxyl group in ricinoleic acid could explain the high 
viscosity of castor oil and its corresponding biodiesel and biolubricant, compared to rapeseed oil. Both biolubricants showed (in general) suitable properties, sometimes better than in the case of the commercial lubricants that were studied.

The kind of alcohol used in biolubricant production seemed to influence some of its characteristics, especially viscosity. The longer and more branched the molecule chain, the higher the viscosity. Consequently, the right choice of the alcohol could optimize the performance of the biolubricant, especially concerning tribology.

For further studies on this subject, analyses to complete characterization of the final biolubricant produced are necessary, paying special attention to IR, mass spectrometry, etc.

Author Contributions: Conceptualization, J.M.E., S.N.-D., and N.S.; methodology, S.N.-D. and N.S.; formal analysis, S.N.-D. and N.S.; investigation, J.M.E., S.N.-D. and N.S.; resources, J.M.E. and J.F.G.; data curation, S.N.-D. and N.S.; writing_-original draft preparation, S.N.-D.; writing—review and editing, J.M.E., N.S. and J.F.G.; visualization, J.M.E. and J.F.G.; supervision, J.M.E. and J.F.G.; project administration, J.M.E. and J.F.G.; funding acquisition, J.M.E. and J.F.G. All authors have read and agreed to the published version of the manuscript.

Funding: This research was funded by Junta de Extremadura and FEDER “Fondos Europeos de Desarrollo Regional", grant numbers GR18150 and IB18028.

Acknowledgments: We would like to thank Junta de Extremadura and FEDER “Fondos Europeos de Desarrollo Regional" for the financial support, and the Research Center "La Orden-Valdesequera" (from Cicytex) for the raw material provided for this research work.

Conflicts of Interest: The authors declare no conflict of interest.

\section{References}

1. Panchal, T.M.; Patel, A.; Chauhan, D.D.; Thomas, M.; Patel, J.V. A methodological review on bio-lubricants from vegetable oil based resources. Renew. Sustain. Energy Rev. 2017, 70, 65-70. [CrossRef]

2. Salih, N.; Salimon, J.; Abdullah, B.M.; Yousif, E. Thermo-oxidation, friction-reducing and physicochemical properties of ricinoleic acid based-diester biolubricants. Arab. J. Chem. 2017, 10, S2273-S2280. [CrossRef]

3. Kania, D.; Yunus, R.; Omar, R.; Abdul Rashid, S.; Mohamad Jan, B. A review of biolubricants in drilling fluids: Recent research, performance, and applications. J. Pet. Sci. Eng. 2015, 135, 177-184. [CrossRef]

4. Sudan Reddy Dandu, M.; Nanthagopal, K. Tribological aspects of biofuels-A review. Fuel 2019, 258, 116066. [CrossRef]

5. Martínez, G.; Sánchez, N.; Encinar, J.M.; González, J.F. Fuel properties of biodiesel from vegetable oils and oil mixtures. Influence of methyl esters distribution. Biomass Bioenergy 2014, 63, 22-32. [CrossRef]

6. Encinar, J.M.; Pardal, A.; Sánchez, N. An improvement to the transesterification process by the use of co-solvents to produce biodiesel. Fuel 2016, 166, 51-58. [CrossRef]

7. Dehghani Soufi, M.; Ghobadian, B.; Atashgaran, M.; Mousavi, S.M.; Najafi, G. Biolubricant production from edible and novel indigenous vegetable oils: Mainstream methodology, and prospects and challenges in Iran. Biofuels Bioprod. Biorefining 2019, 13, 838-849. [CrossRef]

8. Chen, J.; Bian, X.; Rapp, G.; Lang, J.; Montoya, A.; Trethowan, R.; Bouyssiere, B.; Portha, J.F.; Jaubert, J.N.; Pratt, P.; et al. From ethyl biodiesel to biolubricants: Options for an Indian mustard integrated biorefinery toward a green and circular economy. Ind. Crops Prod. 2019, 137, 597-614. [CrossRef]

9. Hajar, M.; Vahabzadeh, F. Modeling the kinetics of biolubricant production from castor oil using Novozym 435 in a fluidized-bed reactor. Ind. Crops Prod. 2014, 59, 252-259. [CrossRef]

10. Saboya, R.M.A.; Cecilia, J.A.; García-Sancho, C.; Sales, A.V.; de Luna, F.M.T.; Rodríguez-Castellón, E.; Cavalcante, C.L. Synthesis of biolubricants by the esterification of free fatty acids from castor oil with branched alcohols using cationic exchange resins as catalysts. Ind. Crops Prod. 2017, 104, 52-61. [CrossRef]

11. Fox, N.J.; Stachowiak, G.W. Vegetable oil-based lubricants-A review of oxidation. Tribol. Int. 2007, 40, 1035-1046. [CrossRef]

12. Hamdan, S.H.; Chong, W.W.F.; Ng, J.H.; Ghazali, M.J.; Wood, R.J.K. Influence of fatty acid methyl ester composition on tribological properties of vegetable oils and duck fat derived biodiesel. Tribol. Int. 2017, 113, 76-82. [CrossRef]

13. Heikal, E.K.; Elmelawy, M.S.; Khalil, S.A.; Elbasuny, N.M. Manufacturing of environment friendly biolubricants from vegetable oils. Egypt. J. Pet. 2017, 26, 53-59. [CrossRef] 
14. Reeves, C.J.; Menezes, P.L.; Jen, T.C.; Lovell, M.R. The influence of fatty acids on tribological and thermal properties of natural oils as sustainable biolubricants. Tribol. Int. 2015, 90, 123-134. [CrossRef]

15. Salimon, J.; Salih, N.; Yousif, E. Biolubricant basestocks from chemically modified ricinoleic acid. J. King Saud Univ. Sci. 2012, 24, 11-17. [CrossRef]

16. Knothe, G.; Razon, L.F. Biodiesel fuels. Prog. Energy Combust. Sci. 2017, 58, 36-59. [CrossRef]

17. Cecilia, J.A.; Plata, D.B.; Maria, R.; Saboya, A.; Murilo, F.; De Luna, T.; Cavalcante, C.L.; Rodríguez-castellón, E. An Overview of the Biolubricant Production Process: Challenges and Future Perspectives. Processes 2020, 8 , 257. [CrossRef]

18. McNutt, J.; He, Q.S. Development of biolubricants from vegetable oils via chemical modification. J. Ind. Eng. Chem. 2016, 36, 1-12. [CrossRef]

19. Mazanov, S.V.; Gabitova, A.R.; Usmanov, R.A.; Gumerov, F.M.; Labidi, S.; Ben Amar, M.; Passarello, J.P.; Kanaev, A.; Volle, F.; Neindre, B. Le Continuous production of biodiesel from rapeseed oil by ultrasonic assist transesterification in supercritical ethanol. J. Supercrit. Fluids 2016, 118, 107-118. [CrossRef]

20. Jose, T.K.; Anand, K. Effects of biodiesel composition on its long term storage stability. Fuel 2016, 177, $190-196$. [CrossRef]

21. Kleinaite, E.; Jaška, V.; Tvaska, B.; Matijošyte, I. A cleaner approach for biolubricant production using biodiesel as a starting material. J. Clean. Prod. 2014, 75, 40-44. [CrossRef]

22. Madankar, C.S.; Dalai, A.K.; Naik, S.N. Green synthesis of biolubricant base stock from canola oil. Ind. Crops Prod. 2013, 44, 139-144. [CrossRef]

23. Verdier, S.; Coutinho, J.A.P.; Silva, A.M.S.; Alkilde, O.F.; Hansen, J.A. A critical approach to viscosity index. Fuel 2009, 88, 2199-2206. [CrossRef]

24. Greco-Duarte, J.; Cavalcanti-Oliveira, E.D.; Da Silva, J.A.C.; Fernandez-Lafuente, R.; Freire, D.M.G. Two-step enzymatic production of environmentally friendly biolubricants using castor oil: Enzyme selection and product characterization. Fuel 2017, 202, 196-205. [CrossRef]

25. Gryglewicz, S.; Muszyński, M.; Nowicki, J. Enzymatic synthesis of rapeseed oil-based lubricants. Ind. Crops Prod. 2013, 45, 25-29. [CrossRef]

26. Encinar, J.M.; González, J.F.; Pardal, A.; Martínez, G. Rape oil transesterification over heterogeneous catalysts. Fuel Process. Technol. 2010, 91, 1530-1536. [CrossRef]

27. Fischer, K.; Schulz, P.; Atanasov, I.; Latif, A.A.; Thomas, I.; Kühnert, M.; Prager, A.; Griebel, J.; Schulze, A. Synthesis of high crystalline tio2 nanoparticles on a polymer membrane to degrade pollutants from water. Catalysts 2018, 8, 376. [CrossRef]

28. Gao, X.; Wang, C.; Xu, Q.; Lv, H.; Chen, T.; Liu, C.; Xi, X. N-doped K3Ti5Nbo14@TiO2 core-shell structure for enhanced visible-light-driven photocatalytic activity in environmental remediation. Catalysts 2019, 9, 106. [CrossRef]

29. Fischer, K.; Gawel, A.; Rosen, D.; Krause, M.; Latif, A.A.; Griebel, J.; Prager, A.; Schulze, A. Low-temperature synthesis of anatase/rutile/brookite $\mathrm{TiO} 2$ nanoparticles on a polymer membrane for photocatalysis. Catalysts 2017, 7, 209. [CrossRef]

30. UNE-EN ISO 3104/AC:1999. Petroleum products. Transparent and opaque liquids. In Determination of Kinematic Viscosity and Calculation of Dynamic Viscosity; ISO 3104:1994; Asociación Española de Normalización: Madrid, Spain, 1999.

31. ASTM-D2270-10. Standard Practice for Calculating Viscosity Index from Kinematic Viscosity at $40^{\circ} \mathrm{C}$ and $100{ }^{\circ} \mathrm{C}$; ATSM International: West Conshohocken, PA, USA, 2016.

32. ASTM-D97-17b. Standard Test Method for Pour Point of Petroleum Products; ATSM International: West Conshohocken, PA, USA, 2017.

33. UNE-EN 116:2015. Diesel and Domestic Heating Fuels—Determination of Cold Filter Plugging Point- Stepwise Cooling Bath Method; Asociación Española de Normalización: Madrid, Spain, 2015.

34. UNE-EN 51023:1990. Petroleum products. Determination of flash and fire points. In Cleveland Open Cup Method; Asociación Española de Normalización: Madrid, Spain, 1990.

35. UNE-EN-ISO-12937:2000. Productos petrolíferos. Determinación de agua. In Método de Karl Fischer por Valoración Culombimétrica; Asociación Española de Normalización: Madrid, Spain, 2001.

36. UNE-EN-55012. Vehículos, embarcaciones y dispositivos propulsados por motores de combustión interna. Características de las perturbaciones radioeléctricas. In Límites y Métodos de Medición para la Protección de Receptores Externos; Asociación Española de Normalización: Madrid, Spain, 2008. 
37. UNE-EN-12634:1999. Productos petrolíferos y lubricantes. Determinación del índice de ácido. In Método de Valoración Potenciométrica en un Medio no Acuoso; Asociación Española de Normalización: Madrid, Spain, 1999.

38. UNE-EN 14111:2003. Fat and oil derivatives. Fatty Acid Methyl Esters (FAME). In Determination of Iodine Value; Asociación Española de Normalización: Madrid, Spain, 2003.

39. Focke, W.W.; Van Der Westhuizen, I.; Oosthuysen, X. Biodiesel oxidative stability from Rancimat data. Thermochim. Acta 2016, 633, 116-121. [CrossRef]

(C) 2020 by the authors. Licensee MDPI, Basel, Switzerland. This article is an open access article distributed under the terms and conditions of the Creative Commons Attribution (CC BY) license (http://creativecommons.org/licenses/by/4.0/). 